\title{
Influence of diabetes mellitus on the oral health of the elderly
}

\begin{abstract}
Introduction: Due to the fast growth of the senior citizens and diabetic in the all Cuban population is possible to predict that requirements in the odontology attention will be greater in the next years. For that reason the prevention and attention in the odontology of the geriatric people is considered a great necessity at the present time and the near future.
\end{abstract}

Objective: To determine the influence of diabetes mellitus in the state of the buccal health care of the senior citizens in the dentistry clinic in Wajay through 2015 to 2016.

Method: A descriptive study of the transversal cut was done. The sample consisted of 634 senior citizens from the three chosen clinics. The buccal exam was completed in order to collect the necessary information. Studied variable: age, sex, risk factors and buccal diseases.

Results: The group of people between $60-74$ years $(23.3 \%)$ this group was the predominant in the diabetic population, females $(60 \%)$. The most frequent periodontal diseases $(15.8 \%)$, the traumatic ulcers $(13.3) \%$ ) And the angular chelitis (7.9\%) just a significant result in the last two examples.

Conclusion: In the diabetic population predominated the group of persons from 60 to 74 years females Unfixed denture was the most represented by xerostomia, smoking, periodontal diseases and traumatic ulcers the buccal diseases was the predominant.

Keywords: diabetes mellitus, senior citizens, deontology of geriatric people
Volume 2 Issue 3 - 2017

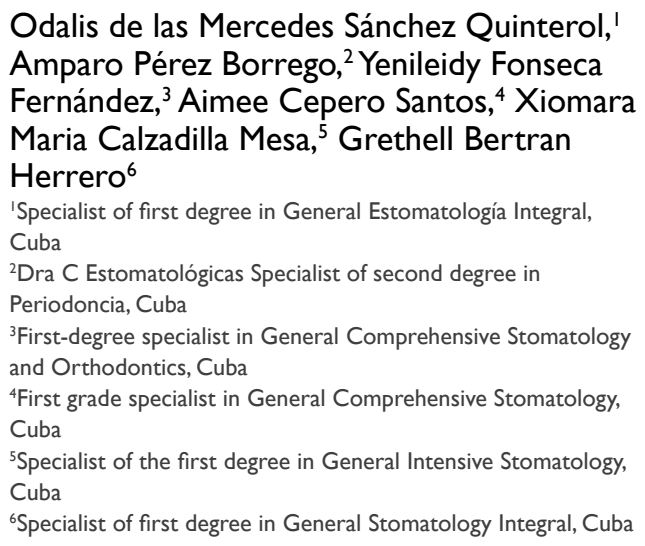

Correspondence: Odalis de las Mercedes Sánchez Quinterol, Specialist of first degree in General Estomatología Integral, Cuba,Tel 6456182, Email odalissanchez@infomed.sld.cu

Received: July 30, 2017 | Published: October 04, 2017

\section{Introduction}

Population aging is considered one of the most important achievements of mankind and is one of the great social problems of the twenty-first century if solutions are not adequate to their consequences, as there are more people every day that exceed the chronological barriers that the Man has placed as a stage of old age and makes it a challenge for modern societies. ${ }^{1}$

According to the latest report from the National Bureau of Statistics (NSO) ${ }^{2}$ the life expectancy at birth of the Cuban population is 77.45 years, $19.4 \%$ of the population is over 60 the population is $60-74$ years old represents $69 \%$ of the elderly. Cuba will be the oldest country in Latin America and it is estimated that by 2050 it will become one of the oldest in the world, figures that reflect the demographic characteristics of aging and give us the measure of what in terms of health, food and nutrition We must prepare ourselves to offer and achieve a better quality of life for the elderly population.

There is a close relationship between diseases of the oral cavity and the control of systemic diseases where diabetes mellitus (DM) in recent years has shown an increase in its prevalence and has reached epidemic dimensions in both developed and developing countries. Are in the process of development it is among the top 10 causes of death during the last decades and currently occupies the seventh cause for what is considered the 21 st century pandemic. ${ }^{3}$

Hyperglycemia is a condition that can favor the development of complications in diabetic patients or accelerate the aging process proper to age, is a disease that affects the whole body and many times the dentist can detect it by certain oral manifestations, which
Although they are not pathognomonic of diabetes, their location and characteristics should make us suspect and request routine analysis. ${ }^{4}$

For all the above and the lack of previous studies in the territory it was proposed to carry out this research with the objective of determining the influence of diabetes mellitus on the oral health of the elderly and identify the risk factors and oral diseases present in this Population

\section{Methodological design}

A cross-sectional descriptive study was carried out in the Wajay health area belonging to the stomatologic clinic of the university polyclinic Dr. Mario Muñoz Monroy "del Wajay, municipality of Boyeros during the period 2015-2016. The universe of study was represented by all older adults dispensed from the health area (8640). A single-stage cluster sampling was performed, where a sample of 653 of the three selected clinics was obtained. The variables studied were: presence of diabetes mellitus, age, sex; Within the risk factors: poor oral hygiene, maladaptive prosthesis, smoking and xerostomia; Oral diseases: dental caries periodontal disease (Russell IP-R Index), angular cheilitis, traumatic ulcer and sub-stomatitis stomatitis. Participants were divided according to WHO in the following age groups.
a. Third age: 60 to 74 years.
b. Fourth age: 75 to 89 years.
c. Longevos: 90 to 99 years.
d. Centenaries: 100 years and more. 
The data were obtained from a form designed to the effect and the individual clinical history. For the information processing, the $\mathrm{Ji}$ square statistic was applied for the association between the qualitative variables with $95 \%$ reliability, the results were taken to an automated database with the Excel 2010 electronic spreadsheet, presented in percentages and were taken to tables and figures created for the better understanding. It was explained in detail to each patient what the research consisted of that only an oral examination would

Figure I Older adults according to age group, sex and diabetes mellitus be performed without any invasive procedure and complying with all established ethical and biosecurity standards.

\section{Results}

In Table 1 the majority of elderly patients were concentrated in the elderly with $136(58.4 \%)$, followed by the fourth age with 70 (35.3\%). Among diabetic patients, women accounted for $57.7 \%$, but no relationship was found between sex and diabetes $(\mathrm{p}=0.107)$.

\begin{tabular}{|c|c|c|c|c|c|c|c|c|c|c|}
\hline \multicolumn{3}{|c|}{ Group of age group } & \multicolumn{4}{|c|}{ Diabetes mellitus } & & & \multicolumn{2}{|c|}{ Total } \\
\hline & \multirow{2}{*}{\multicolumn{2}{|c|}{$\mathbf{F}$}} & \multirow{2}{*}{\multicolumn{2}{|c|}{$\begin{array}{l}\text { SI } \\
\text { M }\end{array}$}} & \multicolumn{3}{|l|}{ No } & & \multirow[b]{3}{*}{ No } & \multirow[b]{3}{*}{$\%$} \\
\hline & & & & & $\mathbf{F}$ & & $\mathbf{M}$ & & & \\
\hline & No & $\%$ & No & $\%$ & No & $\%$ & No & $\%$ & & \\
\hline $60-74$ & 83 & 57,7 & 50 & 52,1 & 136 & 61,3 & 113 & 59,2 & 382 & 58,4 \\
\hline $75-89$ & 54 & 37,5 & 39 & 40,6 & 70 & 31,5 & 67 & 35 & 230 & 35,3 \\
\hline $90-99$ & 7 & 4,8 & 7 & 7,3 & 8 & 3,6 & 11 & 5,8 & 33 & 5,1 \\
\hline I00y more & 0 & 0 & 0 & 0 & 8 & 3,6 & 0 & 0 & 8 & $\mathrm{I}, 2$ \\
\hline Total & 144 & 100 & 96 & 100 & 222 & 100 & 191 & 100 & 653 & 100 \\
\hline
\end{tabular}

Figure 1 shows that approximately half of the patients had poor oral hygiene (51.8\%); among diabetics, they were slightly less affected $(18.5 \%)$ but without a significant relationship $(\mathrm{p}=0.658) .59 .1 \%$ of the patients had impaired prostheses, the proportion was slightly higher in diabetics $(22.0 \%)$ but without a significant association $(\mathrm{p}=0.788)$. Among diabetics the prevalence of smoking was higher $(12.1 \%)$ but there was no relationship between the variables $(\mathrm{p}=0.114)$. Xerostomia was detected in almost half of the older adults $(49.3 \%)$; among diabetics, the proportion of cases with xerostomia was higher $(21.4 \%)$ but the relationship was significant $(\mathrm{p}=0.001)$.

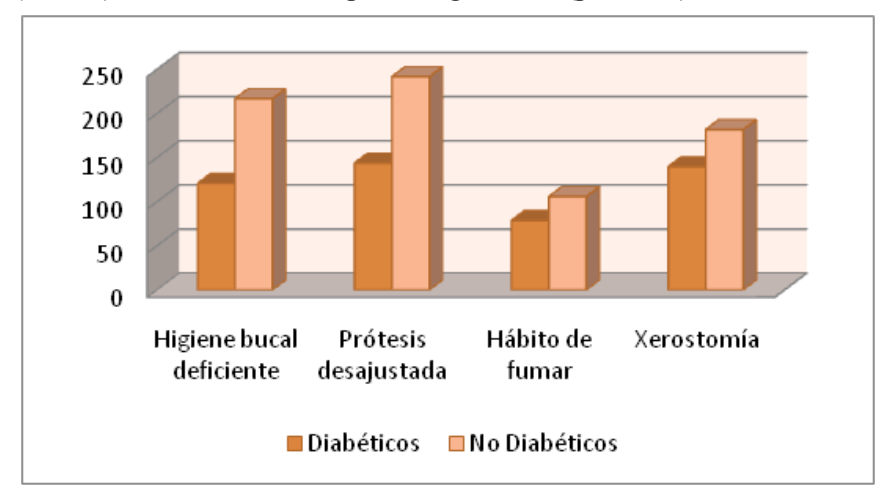

Figure I Major adults according to the presence of risk factors and diabetes mellitus.

\section{Association of qualitative variables}

Pearson's Chi-square *x2=0.196 $1 \mathrm{gl} \mathrm{p}=0.658$ Figure 2 provides that in the diabetic population, periodontal disease ranked first with $(58.3 \%)$. The relationship between angular cheilitis and diabetes was significant $(7.9 \%$ in diabetics vs $0.2 \%$ in non-diabetics), traumatic ulcer $(13.3 \%$ in diabetics vs $6.3 \%$ in non-diabetics) and stomatitis ( $14.6 \%$ in diabetics vs $23 \%$ in non-diabetics). In all these cases $\mathrm{p}<0.05$ Source. Form Statistical significance $\mathrm{p}<0.05$.

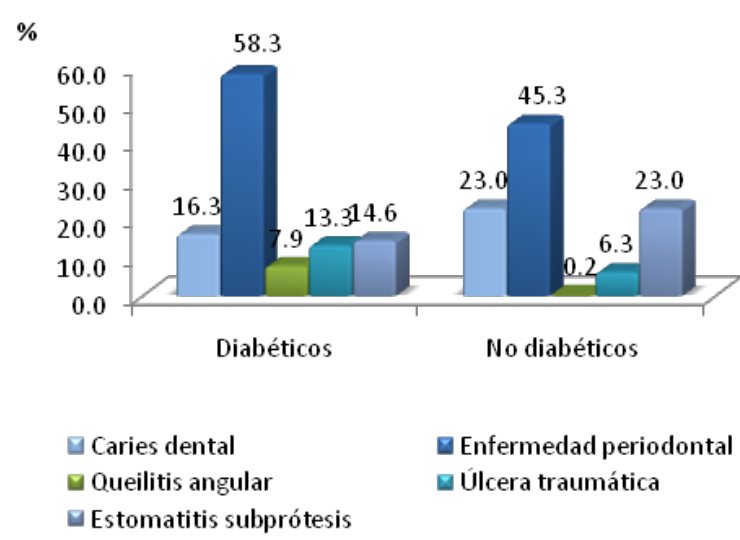

Figure 2 Older adults according to the presence of oral diseases and Diabetes mellitus.

\section{Discussion}

The diabetic population occupied $36.8 \%$ of the total population, which does not correspond to a study carried out in Japan ${ }^{5}$ where the predominant disease was cardiovascular and osteoporosis where they reported a close relationship between systemic and oral diseases and whether it coincides With the results of several researchers in Cuba. ${ }^{1,3,4}$ An epidemiological study corroborates that diabetes mellitus occurs in the adult population, female sex and very related to obesity and is between two and six percent of the total diabetic population. ${ }^{6}$

It is known that patients with DM increase daily, it is in the adult population that the disease reaches its highest prevalence and it is a universal problem but solutions are provided to its consequences considering it the 21 st century pandemic.,

The prevailing age group was 60-74 and the female sex. International studies ${ }^{6-8}$ and national studies ${ }^{3,5,10}$ coincide with the 
results obtained away from the values of García Alpízar, ${ }^{9}$ Ramón Jiménez Ruth et al. ${ }^{11}$ Technical scientific progress, increased life expectancy and quality of care increase the Possibility of having more elderly diabetics; where women due to psychosomatic disorders that suffer from stress, pregnancy and after the climacteric make them more vulnerable to suffering from the disease.

The high presence of risk factors secondary to the biological deterioration of the diabetic elderly, makes them more vulnerable to oral diseases; Oral hygiene was deficient in most of them, both diabetic and non-diabetic, coinciding with international studies ${ }^{6,12}$ and in Cuba. ${ }^{11}$ These results differ from those obtained by Cardentey García, et al. ${ }^{13}$ in Pinar del Rio where older adults were unaware of the care of their oral health and of their prosthesis.

Patients with chronic diseases are more likely to attend health centers and acquire a better education in general and oral health care. It is important to strengthen health education in these population groups so that future generations will reach the age of 60 aware that diseases are not inevitable processes of aging and to the extent that more preventive action is taken Raise the quality of life.

The misfit prostheses ranked first as a risk factor for oral diseases in the study population; These data coincide with the studies carried out in Brazil by Lima, et al. ${ }^{8}$ and in Chile by Gutierrez, et al. ${ }^{13}$ although it is opportune to point out that the coincidence is due to the prolonged use of the prosthesis in these patients due to the impossibility of accessing the services Health because of its low economic level. Cardentey García, et al. ${ }^{14}$ in Pinar del Rio found that only $15 \%$ needed to change their prosthesis because they were in poor condition and did not comply with aesthetic and functional principles these data are lower than those reported in the present investigation.

All this is explained by the fact that females use their prostheses for longer periods of time than males because they do not accept being seen without them because they are concerned about their esthetics which has a significant role in the results obtained.

Smoking had a slight predominance in the diabetic population these results do not coincide with those reported in Japan ${ }^{6} \operatorname{Spain}^{15}$ where it was the most prevalent risk factor. A study conducted in $\mathrm{Cuba}^{11}$ agrees with these data smoking is one of the risk factors that influence the appearance and aggravation of entities such as inflammatory periodontal disease, premalignant and malignant lesions in the oral cavity which are very common In this population group. In another study carried out in Pinar del Rio by Pérez Hernández, et al. ${ }^{10}$ reports that the oral lesions did not correspond to this habit.

Chronic tobacco consumption is currently a social phenomenon that affects all sectors of the population, is considered an important risk factor in the morbidity and mortality in Cuba, affecting both general health and oral health4. This leads us to reflect on the practice of health promotion actions in the community aimed at guiding changes in the gerontans' lifestyles.

Xerostomia was another risk factor that predominated in the studied population, mainly in the diabetic population. The results obtained coincide with those reported in Bolivia by Villa A, ${ }^{16}$ Otero Rey et al. ${ }^{17}$ in Spain, but differs with those of Laplace Pérez1 in Holguín, who argued that it was caused mainly by ingestion of drugs.

In the elderly population this risk factor is very frequent, not only due to the morphological changes that it undergoes during its aging process but also due to the ingestion of medication by the chronic diseases that suffer from it and in patients with DM it is present within its symptoms (Polydixia) which corresponds to the results obtained where there was statistical significance.

In the present study more than half of the population was affected by chronic inflammatory periodontal disease with apredominance in the diabetic population. Studies conducted in Mexico ${ }^{15}$ and Chile ${ }^{18}$ found that almost all of the individuals studied were affected, so they do not coincide with the results obtained. Two studies in $\mathrm{Cuba}^{4,14}$ corroborated that diabetes mellitus constitutes an important risk factor in the development of periodontopathies the latter being considered the first cause of tooth loss after the 40 years of life and is the most frequent complication in the Population, has a bidirectional relationship.

Traumatic ulcers were the second most prevalent in the diabetic population, coinciding with a study carried out by Martori et al.$^{19}$ in Spain, where he reported that his presence was related to maladjusted prostheses. In Antioquia Colombia Moreno JA et al. ${ }^{20}$ the presence of traumatic ulcer was related to cardiovascular diseases although they also appeared in diabetic patients but in a smaller proportion. Other studies carried out in $\mathrm{Cuba}^{11,14}$ differ from the present since the subpothesis stomatitis was the most prevalent disease in the elderly population.

It is important to remember that in the elderly diabetic population this lesions are very frequent because their mucous membranes are more susceptible to laceration due to traumas of occlusion caused during the chewing of hard foods, sharp edges of prostheses, defective restorations, which are slow to heal and therefore make them more susceptible to infections.

The relationship between angular cheilitis traumatic ulcers and sub-stomatitis with DM was significant. These results coincide with those reported by Martori ${ }^{19}$ in Spain where it was related to poor oral hygiene and maladjusted prostheses. Changes suffered by the older adult in the facial muscles, tooth loss and maladaptive prothesis that cause a decrease in the vertical dimension and this makes him very vulnerable to suffer the disease.

It is the role of the stomatologist to help these patients to maintain good oral health by identifying risk factors, recognizing and differentiating the normal changes characteristic of the age of the pathological ones and the solution of the oral health problems that affect them to offer them a better quality of life. ${ }^{1}$

\section{Conclusion}

i. In diabetic patients, it was predominantly in the 60-74 age groups and in the female sex.

ii. The maladaptive prosthesis, smoking and xerostomia were the risk factors that prevailed in diabetic older adults.

iii. Chronic inflammatory periodontal disease and traumatic ulcer predominated in the diabetic population

\section{Acknowledgements}

None

\section{Conflict of interest}

The authors declare that they have no competing interests. 


\section{References}

1. Beatriz LN, Legrá MSM, Fernández LJ, et al. Oral diseases in the elderly. Correo Científico Médico. 2013;17(4):477-488.

2. Ministry of Public Health. National Directorate of Medical Records and Health Statistics. Statistical Yearbook of Health 2015. Havana, Cuba; 2015.

3. Dot PLC, Díaz CM, Pérez LJ, et al. Clinical, epidemiological characteristics of diabetes mellitus in the elderly. University Policlinico Luís A Turcios Lima. Rev Medical Sciences. 2011;15(2):157-169.

4. María HMD, Margarita RMM, Francisco LG, et al. Diabetes mellitus as a risk factor for tooth loss in the geriatric population. Rev Medical Sciences. 2010;14(1):17-25.

5. Yusimy AC, Manolo GJ, Marieta VG, et al. Clinical epidemiological behavior of diabetes mellitus in the elderly. Rev Medical Sciences. 2013;17(3):92-101.

6. Ozcaka O, Becerik S, Bicakci N, et al. Periodontal disease and systemic diseases in an older population. Arch Gerontol Geriatr. 2014;59(2):474-479.

7. Christopher MC, Teresa JC, Ángel CB, et al. Behavior of the Geriatric/ General Oral Health Assessment Index (GOHAI) and Oral Impacts on Daily Performances (OIDP) in a population of older adults in Mexico City. Rev Odont Mex. 2014;18(2):111-119.

8. Isabella LAR, Helena PVH, Keny CDS. Characterization of oral health of the elderly in a long-stay charity in João Pessoa-PB, Brazil. Rev Cubana Estomatol. 2012;49(3):193-203.

9. Alpízar GB, Valladares CM, Morales MOT. Total prostheses and oral lesions in institutionalized older adults. 2012;2(1):12.

10. Yaimara PH, Danisbel PA, Planes EM, et al. Prosthetic rehabilitation in the oral lesions of the elderly. Rev Medical Sciences. 2015;19(1):13-23.
11. Ruth RJ, Maritza MR, Olaydis HMB, et al. Characterization of older adults with premalignant and malignant oral lesions. MEDISAN. 2015;19(6):730-737.

12. Gabardo MC, Moysés SJ, Moysés ST, et al. Social, economic and behavioral variables associated with oral health-related quality of life among Brazilian adults. Cien Saude Colet. 2015;20(5):1531-1540.

13. Carmen GG, Luis BM, Marcela S, et al. Subprotésica Stomatitis in Patients of Region IX, Chile. Int J Odontostomat. 2013;7(2):207-213.

14. Juan CG, Enrique TOP, Mercedes SCA, et al. Oral health status of the geriatric population belonging to Ormani Arenado Clinic. Rev Medical Sciences. 2011;15(2):76-86.

15. Aranza TO, Coronel CX, Palacio HRD. Profile of Oral Health in a group of Older Adults of the Hidalgo State. Aceptado para publicación. 2014;71(2):77-82.

16. Villa A. Dental patients' self-reports of xerostomia and associated risk factors. J Am Dent Assoc. 2011;142(7):811-816.

17. Otero RE, Mallón PMM, Piñón RM, et al. Oral candidiasis in the elderly patient. Av Odontoestomatol. 2015;31(3):135-148.

18. González RC, Chamorro SJ, Schwerter RV, et al. Periodontal status and need for treatment in GES patients 60 years of Villa Alemana. Rev Clin Implantol Periodontics Rehabil Oral. 2010;3(2):86-89.

19. Martori E, Montero AR, Gomis MJ, et al. Risk factors for dentalrelated oral mucosal lesions in a geriatric population. J Prosthet Dent. 2014;111(4):273-279.

20. Moreno JA, Montoya AF, Gómez DP, et al. Situation of oral health and prosthetic status of the edentulous bimaxilar patient who attends the Faculty of Odontology of the University of Antioquia: a pilot study. Rev Fac Odontol Univ Antioq. 2012;24(1):22-36. 